\title{
HUMAN (IN)CONSISTENCIES IN IAN MCEWAN'S AMSTERDAM
}

\author{
FLORENTINA ANGHEL \\ University of Craiova
}

\begin{abstract}
Ian McEwan's Amsterdam has supplied its readers with psychological, moral and social topical issues presented in an easy flowing and exhilarating style. Starting from the assumption that life consists of a series of inconsistencies which are inherent and bring their contribution to the individual's formation, the paper aims at demonstrating that the protagonists' judgmental and moral inconsistencies, which are used as a plot generator and are environmentally determined, reveal features of their personality.
\end{abstract}

Keywords: consistency, inconsistency, judgmental inconsistencies, moral inconsistencies, novel.

\section{Introduction}

Ian McEwan's Amsterdam is widely perceived as different from his previous novels both as "a kind of writing experience", as the author admits in an interview (McEwan, Interview, 1998 qtd. in Childs 2006:120), and as a finite product, since the readers' opinions vary from very appreciative ones, resulting in the Booker Prize in 1998, to critical ones which fail to adhere to its pattern breaking newness. However, beyond its apparent shallowness and easily flowing style, the novel plays with overlapping and often sliding planes of human behaviour which, changing in time and space, reveal inconsistency as a consistent feature of human nature.

\section{Consistency/ Inconsistency}

(In)consistency, roughly seen as (dis)agreement or lack of coherence among things or parts, is related to the continuous change of man's "knowledge base" (Perlis 1997:15) as part of the cognitive process which cannot be entirely controlled. An individual's mind receives new data which are processed on the background of the already existing data, meaning that one's mind is always active and is in a permanent change. Irrespective of whether we apply the pattern of Wolfgang Iser's (1974) phenomenological reader of the surrounding "text of the world" or the one of the mind receiving "myriad impressions", according to Virginia Woolf (1966:105), or of the data receiving mind, there is a consensus theory according to which the knowledge basis keeps changing. On the one hand, new information enters the individual's knowledge basis and changes it, some pieces of information may be in agreement and only enlarge the basis without affecting his/her consistent attitude or behaviour while others may be in conflict, therefore inconsistent with former knowledge, which may lead to a change of attitude; on the other hand, the mind aims to accommodate the new information or to regain the agreement between its parts. Therefore, the information is processed so as to surpass the conflict and find a solution which may either re-establish the former state or establish a new attitude. 
The dichotomy consistency/inconsistency, mainly explored in psychology, has found its utility in various domains, from economics to cybernetics and political sciences, which are related to decision making and behavioural changes. Researchers have thus identified sources and types of inconsistencies. The sources of inconsistencies are associated with the new information the already existing knowledge basis receives, with the relation between expectations and data inconsistency, or with the time-space component. As mentioned above, the knowledge basis is in a continuous change due to the ever coming information that may either agree or disagree with its parts. The reception of new information cannot be entirely controlled and the mind goes through a process of checking the data, in case it disagrees with the other elements and leads to conflict, therefore through a period of confusion or inconsistency, until the solution is found (Perlis 1997:14).

Another source of inconsistency is associated with the type of memory based on more or less stereotypical beliefs. Küppers and Bayen (2014:2043-2044) make the difference between schema-consistent information and schema-inconsistent information, which are less well and respectively better remembered. In their analysis, founded on the research of Gawronski et al. (2003) and of Stangor and McMillan (1992), they share the idea of this "connection between expectancy strength and the occurrence of inconsistency effects." However, they also agreed on the fact that stronger stereotypical beliefs lead to "better memory for inconsistent stereotypes", while "weaker stereotypical beliefs [show] no difference in memory". (Küppers and Bayen 2014:2043-2044)

Human inconsistency also depends on time and space. Starting from psychologists' and economists' conclusion that people generally are inconsistent at different times, Prince and Shawhan demonstrate that men are more often inconsistent than women are, and therefore show a tendency towards procrastination and making choices "with long term costs or risks against their own prior wishes" (Prince and Shawhan 2011:501). As regards space, people's movement from one place to another implies a change of their beliefs and attitudes sometimes in connection with the expectancy strength and with the difference between home, implying stability/consistency, and other places. Spatial exploration supposes the desire to discover new data and feel new emotions which may cause inconsistency.

Since inconsistency is associated to knowledge acquisition, it is, according to Perlis (1997:16), "not only necessary as a component of commonsense reasoning, but is even a good thing, a guide to rational decision making." He also mentions the fact that the opponents consistency/inconsistency have both positive and negative features as follows: "Somehow consistency carries an aura of sense, solidity, correctness, and its opposite - inconsistency an aura of incorrectness, sloppiness, nonsense." (Perlis 1997:16) Such features have determined the association of inconsistency with misjudgements and with the lack of morality, a direction that McEwan follows in his novel. However, "strict adherence to consistency also carries an aura of hidebound inflexibility, unwillingness to consider new ideas", which eventually leads to periods of inconsistency. On the other hand, from moments of inconsistency new ideas, "new insights and re-interpretations" often emerge (Perlis 1997:16).

Since inconsistencies are unavoidable in people's life, they also represent an important ingredient in literature, which mainly speculates on conflicts and turning points in characters' evolution. In Amsterdam McEwan (2005) explores a drift from life's smoothness and imagines a quest for a solution or a return to stability which can be interpreted as a concatenation of events causing judgemental and moral inconsistencies.

\section{Inconsistency As a Plot Generator}


Within the economy of the narrative, inconsistency acts as a generator of tension and makes the story unfold. Disturbing the stability of the characters' lives, an inconsistency launches an inner conflict and an implicit quest for the initial state of calmness. McEwan's Amsterdam shows how unexpected events lead to inconsistent behaviour in the story of two friends, Vernon and Clive, whose common friend, Molly, died due to her mental decline. This sudden death creates a moment of crisis which makes the two friends decide upon assisting each other in euthanasia if they enter such a decline. Following the structure and the well dosed pace of a play, without lingering in descriptions, the novel rests on Vernon and Clive's inner conflict: Molly's mental decline resulting in sudden death. 'Sudden' carries the burden as it implies weak or no expectancy marking a lasting memory and a problem they have to deal with. The strong impact Molly's death had on the two characters is fuelled by their love for Molly and the time they had spent together. Therefore, besides the fact that new data are added to their knowledge basis, they have to accommodate to the new situation, reason and find a commonsense solution. Since death is irreversible, they start worrying about their own death and find a provisional solution in their agreement which is meant to spare them the embarrassment Molly had been through. Yet, their vow generates new unexpected circumstances, a sequence of inconsistencies and suspicion, which force them to keep searching for a solution to restore stability.

Clive's inconsistent behaviour determined by the new situation consists of the delay in finishing the Millennial Symphony, of the failure to help a woman who was being raped while he was creating, of the change of his feelings towards Vernon as he had noticed the changes in Vernon's attitude and beliefs (Vernon's inconsistencies), his failure to recognize the man who had raped the woman or to anticipate his friend's behaviour. Vernon, in his turn, in his attempt to meet his readers' recognition by publishing the pictures of Garmony and when he decides to poison Clive in the end without caring about Clive's possibility to do the same, shows a different behaviour arising from his inconsistencies.

An analysis of the inner and outer planes of the novel shows that the protagonists as well as the author go through challenging experiences which determine behavioural changes as evidence of their bias towards procrastination. McEwan admits the pleasurable effect the experience of writing Amsterdam had on him:

It was a real pleasure to write Amsterdam. If I had to characterize my mood, I wrote in a state of glee. It was a very different kind of writing experience from Enduring Love, which was full of almost nightmare intensity - which in itself was exhilarating. But this had a quality of...I kept thinking, 'If nobody else likes it, I don't give a damn, because I really am having fun.' (McEwan, Interview, 1998 qtd. in Childs 2006:120)

McEwan's emotions associated with the two novels are different, even contradictory, which reveals his inconsistencies with himself/his creative selves. This very confession restates the well known fact that an artist has multiple personalities or authorial selves or masks which change from work to work. Clive Linley, a composer himself, should be expected to reveal his creative personalities, although the novel covers only the period when he is working on a symphony.

Echoing the emotional changes in both the author and his characters, as well as the fluctuant plot, critics and readers shared contradictory impressions. The novel was awarded the Booker Prize, which proves its qualities in terms of narrative devices, for instance, used in an easily flowing and exciting narrative. There were also voices rising rather from impressions that the novel may give, such as a simple and "preposterous" plot or the use of an "irritating" tone (Jordison 2011), and which considered it McEwan's worst novel. But Amsterdam is a novel completely adequate to its time: short, entertaining, flowing rapidly among apparently distracting loops of memory or rhythm, resulting in conflicts and suspense. 
The author's joy and emotions were transferred to the narrative, yet they were harshly rejected by readers who failed to see the beauty in variations of intensity and changes of rhythm. Eventually the inconsistency is in the reader's eye and is a result of the reader's expectation.

Procrastination, misjudgements and moral hypocrisy, aspects that will be identified in the characters' behaviour, attend the inconsistencies in the protagonists' evolution and also stand for basic tendencies of their personalities.

\section{Inconsistencies of Judgement}

A highly determinant role in judging or making decisions lies in the context - meaning knowledge basis, time, space, situation - which influences people's feelings and way of thinking. According to Perlis (1997:14), any new piece of information creates a state of confusion until it is understood, recognized as true and assimilated, and contributes to the enlargement of the knowledge basis. The information or knowledge basis undoubtedly varies in time; therefore, a person's attitude as a result of the same information may be different at different times. Besides this time inconsistency, other more flexible factors such as a person's mood, which often is rendered or influenced by space or by the interaction with other people, can determine his/her behaviour.

In Amsterdam the characters' change of attitude in relation with space is obvious and extensively exploited. Open and public spaces require a kind of behaviour in accordance with social rules; houses and rooms provide a more intimate space that reveals a less formal or even hidden side of the characters. For example, Clive lives in disorder when he creates:

The house had a closeted atmosphere and he [Vernon] guessed that Clive had not been out for a day or two. A half-opened door revealed the bedroom to be in a mess. He sometimes asked the housekeeper not to come in when he was working hard. The state of the studio confirmed the impression. (McEwan 2005:47)

While such short-term and routine variations, which are deliberately adhered to, do not count as inconsistencies, other more striking, isolated and unexpected situations resulting in longterm disturbances and obvious changes of behaviour are to be analysed.

Molly's funeral, including the journey to the cemetery and the meeting with George and Garmony, and Vernon's visit to her room, seasoned with George's memories about her mental decline in contrast with Clive's and Vernon's memories about the Molly they knew, are two experiences with a strong emotional impact. Clive, for instance, feels powerful sensations that he considers "simple night fear" but which are instilled by Molly's death:

His feet were icy, his arms and chest were not. Anxieties about work transmuted into the baser metal of simple night fear: illness and death, abstraction which soon found their focus in the sensation he still felt in his left hand. (...) Wasn't this the kind of sensation Molly had when she went to hail that cab by the Dorchester? He had no mate, no wife, no George, to care for him, and perhaps that was a mercy. But what instead? (...) He would see a doctor in the morning. But that's what Molly did, and they sent her off for tests. They could manage your descent, but they couldn't prevent it. Stay away then, monitor your own decline, then when it is no longer possible to work, or live with dignity, finish it yourself. But how could he stop himself passing that point, the one Molly reached so quickly, when he would be too helpless, too disoriented, too stupid to kill himself? (McEwan 2005:25)

Their commonsense reasoning, assuming the situation has been understood, resorts to an extreme solution mirroring panic and nonconformism:

Just supposing I did get ill in a major way, like Molly, and I started to go downhill and make terrible mistakes, you know, errors of judgement, not knowing names of things or who I was, that kind of thing, 
I'd like to know there was someone who'd help me to finish it ... I mean, help me to die. (McEwan 2005:49)

Both Vernon and Clive fail to notice the context that determined the intensity of their feelings and their mental and behavioural sideslip at this very moment. Had Molly not been their close friend and had they considered the changes that may appear in time, they wouldn't have made the vow. It is actually the proof of their first inconsistency of judgement.

Besides, the vow has an anticipatory effect as it elicits the reader's expectation for death in at least one of the characters. Consequently, inconsistency becomes an engine that makes the narrative coherently continue with changes and that turns the two friends into enemies. The conflict arises from Vernon's disagreement with Clive's not having helped the woman in the Lake District and Clive's disagreement with Vernon's decision to publish the pictures that George had given to him. Vernon asked Clive to go to the police to tell them what he had seen otherwise he would go himself, Clive "emerged from a tunnel into clarity", that is into understanding what kind of "Vermin" his friend was, and later decided to send him a "poisonous card": "Your threat appals me. So does your journalism. You deserve to be sacked. Clive." (McEwan 2005:138) This attitude towards each other somehow echoes their inner and unspoken beliefs, as they both have an intuition of their wrongdoings, beliefs that they eschew by hiding behind "reasoning". This disagreement with each other and with themselves is a result of time and space inconsistencies, including imaginary ones.

Another inconsistency lies in Clive's failure to anticipate Vernon's behaviour and Vernon's failure to anticipate Clive's and it comes at the end when they kill each other in the same way, despite their fundamental similarity of character. Their commonsense reasoning hinders them from doing it in England, from breaking the law and being common murderers. Their behaviour is geographically inconsistent, as it adapts to the place where they are. In their decisions they harmonize their inner wishes with the geographical opportunities to get maximum satisfaction: the mountains of the Lake District are supposed to provide Clive with inspiring loneliness and he counts on privacy when he decides upon not telling the police about the rape; Amsterdam means openness and freedom.

\section{Moral Inconsistencies}

Amsterdam is often interpreted as a moral novel due to the dilemmas around which the story is woven. "Amsterdam has the briefness, the relatively simple characters, the clear moral and social dilemmas that are associated with the genre. Clive and Vernon are each confronted with a moral dilemma, and each makes a disastrous decision." (Malcom 2002:194) The protagonists' 'moral dilemmas' are, according to Hertwig and Hoffrage, "moral inconsistencies" which cause inconsistent behaviour. In their opinion, "focusing on internal traits may obstruct our view of the external world", therefore moral inconsistencies are environmentally determined and classified as follows: "inconsistencies in moral behaviour across situations" - people who used to be ethical in the past but within a context, which is misunderstood or misinterpreted, suddenly do bad things -, "inconsistencies between moral judgment and reasoning" - when people support their deeds with false post hoc reasons -, and "inconsistencies between moral judgment and behaviour" - when people lie despite their being against lying (Hertwig and Hoffrage 2013:464). The last category is also called "moral hypocrisy" and seen as a source for behavioural inconsistency by Monin and Merritt (2011).

Moral inconsistencies are easy to identify in both Clive's and Vernon's behaviour and judgement. Being under time pressure with his Millennial Symphony, Clive decides to take an inspirational journey to the Lake District. Along the route he takes he sees a woman and a man during an argument and an attempt to rape, and refrains from helping the woman, being afraid that "the murmur of a voice" (McEwan 2005:84) which is inspiring him may disappear. 
He chooses to be absent: "I am not here." (McEwan 2005:85), revealing his selfishness and the two sides of his personality in the description below. There is, however, an obvious overlapping of imaginary and real planes, since he treats reality as a hypothesis ("if she needed protection"). His decision not to interfere shows his moral slippage in the style of dark comedy:

\begin{abstract}
He was crossing out notes as fast as he was setting them down, but when he heard the woman's voice rise to a sudden shout, his hand frozen. He knew it was a mistake, he knew he should have kept writing, but once again he peered over the rock. [He imagines a scene in which he saves the woman and they leave together.] Even this least probable of outcomes would destroy his fragile inspiration. [...] Their fate, his fate. The jewel, the melody. Its momentousness pressed upon him. [...] What was clear now was the pressure of choice: he should either go down and protect the woman, if she needed protection, or he should creep away $[\ldots]$ to find a sheltered place to continue his work - if it was not already lost. [...] It was as if he wasn't there. He wasn't there. He was in his music. His fate, their fate, separate paths. (McEwan 2005:86-89)
\end{abstract}

Although less usual experiences, which may be considered 'schema-inconsistent information', are expected to be well remembered, Clive fails to remember the face of the man who raped the woman when he is taken to the police. This ranges him among people with "weaker stereotypical beliefs" (Küppers and Bayen 2014:2044). The solution he found to his brief conflict of whether to help the woman or not shows his selfishness.

Similarly, Vernon reveals his moral inconsistency when he claims he wants to publish the pictures Molly had taken of Garmony in woman underwear and clothes. He invokes his responsibility as an editor and ignores the moral prejudice he could bring to Molly's memory. While Clive gets sensitive to this moral issue, as a result of his friendship for Molly, Vernon, just like his friend writing the symphony during the journey, believes in the success the newspaper The Judge will have due to the publication of the pictures. He presents a reason of social and economic interest, which hides his personal aim and betrays his friendship for Molly, revealing an inconsistency between moral judgment and reasoning.

Clive! Listen to me. You're in your studio all day dreaming of symphonies. You've no idea what's at stake. If Garmony's not stopped now, if he gets to be a prime minister in November, they've got a good chance of winning the election next year. Another five years! There'll be even more people living below the poverty line, more people in prison, more homeless, more crime, more riots like last year. He's been speaking in favour of national service. (McEwan 2005:74)

Their disagreement with each other evolves into an apparent betrayal: Clive sends the poisonous card to Vernon who does not receive the criticism well and goes to the police to tell them that Clive witnessed the rape. Unexpectedly, Clive cannot identify the man who raped the woman, which reflects his total detachment and/or loss of memory. Each identifies the other's inconsistent behaviour consisting of misjudgements, moral inconsistency and loss of memory, and decides to act according to the vow.

\title{
6. Conclusions
}

Irrespective of whether inconsistencies are perceived as the frequent inner conflicts emerging out of a challenged knowledge basis daily assaulted by new information, as inconsistencies of judgement determined by situations or misunderstandings, or as moral inconsistencies arising from the conflict between people's declared adherence to moral principles and their deeds - everybody confronts them and learns to identify them, solves them and uses the results in a process of evolution. Being inconsistent is part of human nature and, as an inherent human trait, it ensures man's consistency, which may even reside in the identification of a behavioural pattern based on the individual's behavioural inconsistencies. 
Clive and Vernon, as particular as they may seem - the composer who was invited to write the Millennial Symphony and the editor of The Judge -, do not succeed in surpassing man's ambition, selfishness, errors and natural fear of death.

\section{References:}

Childs, Peter (Ed.). 2006. The Fiction of Ian McEwan. A reader's guide to essential criticism. New York: Palgrave Macmillan.

Gawronski, Bertram, Katja Ehrenberg, Rainer Banse, Johanna Zukova and Karl Cristoph Klauer. 2003. "It's in the mind of the beholder: The impact of stereotypic associations on category based and individuating impression formation". Journal of Experimental Social Psychology 39:16-30.

Hertwig, Ralph, Ulrich Hoffrage and the ABC Research Group. 2013. Simple Heuristic in a Social World. New York: Oxford University Press.

Iser, Wolfgang. 1974. The Implied Reader. Baltimore: Johns Hopkins UP.

Jordison, Sam. 2011. "Booker Clud: Amsterdam by Ian McEwan, Characters without personality, comedy without mirth - how McEwan's worst novel won the Booker is a deep mystery". The Guardian, 6 December [Online]. Available: http://www.theguardian.com/books/2011/dec/06/booker-clubamsterdam-ian-mcewan [Accessed 2015, May18].

Küppers, Viviane and Ute J. Bayen. 2014. "Inconsistency effects in source memory and compensatory schemaconsistent guessing". The Quarterly Journal of Experimental Psychology 67(10):2042-2059, DOI: 10.1080/17470218.2014.904914, Publisher: Taylor \& Francis. [Accessed 2015, June10].

Malcom, David. 2002. Understanding Ian McEwan. Columbia: South Carolina Press.

McEwan, Ian. 2005 (1998). Amsterdam. London: Vintage.

Monin, Benoit and Anna Merritt. 2011. "Moral hypocrisy, moral inconsistency, and the struggle for moral integrity". The social psychology of morality: Exploring the causes of good and evil, Herzliya Series on Personality and Social Psychology, Vol. 3. Mario Mikulincer \& Philip Shaver (Eds.). Washington, DC: American Psychological Association, pp. 167-184.

Perlis, Don. 1997. "Sources of, and exploiting, inconsistency: preliminary report". Journal of Applied NonClassical Logics 7(1-2):13-24, DOI:10.1080/11663081.1997.10510899, Taylor \& Francis. [Accessed 2015, June 10].

Prince, Jeffrey T. and Daniel L. Shawhan. 2011. "Is time inconsistency primarily a male problem?". Applied Economics Letters 18(6):501-504, DOI: 10.1080/13504851003761806, Routledge. [Accessed 2015, June 10].

Stangor, Charles and David McMillan. 1992. "Memory for expectancy-congruent and expectancy-incongruent information: A review of the social and social developmental literatures". Psychological Bulletin 111:42-61.

Woolf, Virginia. 1966. "Modern Fiction”. Collected Essays, Vol. 2. Leonard Woolf (Ed.). London: Hogarth.

\section{Note on the author}

Florentina ANGHEL is an Associate Professor in twentieth-century English and Irish literature, contemporary British and American drama and literary theory at the University of Craiova, Romania. Holder of a Ph.D. in literature, she is the author of three books and more articles in her domains of research and areas of teaching. 